\title{
IgG antiglobulin levels in patients with psoriatic arthropathy, ankylosing spondylitis, and gout
}

\author{
F. A. HOWELl, M. A. Chamberlain, R. A. PERRY, G. TORRigiani, \\ AND I. M. ROITT \\ From the Department of Rheumatology and Physical Medicine, and the Department of Immunology, Middlesex \\ Hospital and Medical School, London
}

Psoriatic arthropathy and ankylosing spondylitis are generally considered as separate conditions from rheumatoid arthritis but they show some marked clinical and pathological similarities. The sheep cell agglutination test is negative in these diseases, in contrast to rheumatoid arthritis, in which it is positive in approximately 80 per cent. of cases in whom the disease is classified as 'classical', 'definite', or 'probable' (American Rheumatism Association, 1959). Although not all antiglobulin factors are capable of agglutinating sheep cells coated with rabbit IgG, they can be demonstrated by a technique which has been devised for the quantitative estimation of such antibodies in the IgM, IgA, and IgG classes (Torrigiani and Roitt, 1967). This depends on the adsorption of antiglobulins onto cross-linked horse gamma globulin and their subsequent elution from this complex and estimation by single radial immunodiffusion using specific anti-immunoglobulin antisera. In this way it has been shown that elevated levels of IgG antiglobulin are present in the majority of patients with 'seronegative' rheumatoid arthritis (Torrigiani, Roitt, Lloyd, and Corbett, 1970). Raised levels were also found in a series of children with active Still's disease but the levels were normal in those in whom the disease was inactive (Torrigiani, Ansell, Chown, and Roitt, 1969).

In the present investigation we have used this technique to estimate the levels of antiglobulin in factors in patients with psoriatic arthropathy and ankylosing spondylitis and have attempted to correlate the results with the degree of disease activity. The results were also compared with those obtained from cases of uncomplicated psoriasis and from a group of patients with gout.

\section{Materials and methods}

\section{CLINICAL MATERIAL}

Group 1 Middlesex Hospital out-patients

This group consisted of sixteen patients with ankylosing spondylitis, sixteen with psoriatic arthropathy, thirteen with uncomplicated psoriasis, and fifteen with gout. These patients were all examined at the time the serum sample was obtained and the severity of joint inflammation or skin involvement was assessed in all patients with arthritis on a clinical basis and graded 1 to 4 . The erythrocyte sedimentation rate was recorded in each case.

The diagnosis of ankylosing spondylitis was made according to the criteria of Bennett and Burch (1967) and was classified as definite in all cases. The duration of disease varied from 4 to 32 years.

Psoriatic arthropathy was diagnosed on the presence of the following features:

(a) Seronegative polyarthropathy,

(b) terminal interphalangeal joint inflammation or radiological erosions;

(c) psoriasis;

(d) absence of nodules or tendon lesions.

The duration of the arthritis in these patients varied from 7 to 36 years.

Each of the patients with gout had had persistent hyperuricaemia (serum uric acid above $6 \mathrm{mg} . / 100 \mathrm{ml}$.) and recurrent attacks of arthritis. All except one was being treated with uricosuric therapy or allopurinol and none was suffering from an acute attack at the time the serum sample was obtained. The serum uric acid was estimated in each case.

\section{Group 2 Patients attending other centres}

This group consisted of 32 cases of ankylosing spondylitis, six of psoriatic arthritis, and eight of gout.

\section{Control group}

The IgG antiglobulin levels in both groups of patients were compared with those obtained from 26 normal controls and 21 patients with osteoarthrosis. These control values were those reported in a previous paper (Torrigiani and others, 1970) and were estimated by the same method. A standard serum was included for each series of tests as a control for the reagents.

\section{QUANTITATIVE IMMUNOADSORPTION OF ANTIGLOBULINS}

Insoluble cross-linked preparations of horse globulin precipitated from horse serum with 40 per cent. ammonium sulphate were made as described by Torrigiani and Roitt (1967) and the estimation of the antiglobulins was carried out as described by Torrigiani and others (1970). 


\section{Results}

Elevated levels of IgG antiglobulins were found in the majority of patients with ankylosing spondylitis and psoriatic arthropathy as compared with the normal controls and cases of osteoarthrosis. These figures compare with the results obtained previously in adult patients with 'seronegative' rheumatoid arthritis, in which 85 per cent. gave values ranging from 40 to $200 \mu \mathrm{g}$. $/ \mathrm{ml}$. Somewhat raised levels were also found in a proportion of patients with uncomplicated psoriasis and gout, though these did not reach the maximum figures observed in ankylosing spondylitis and psoriatic arthropathy (Figure).

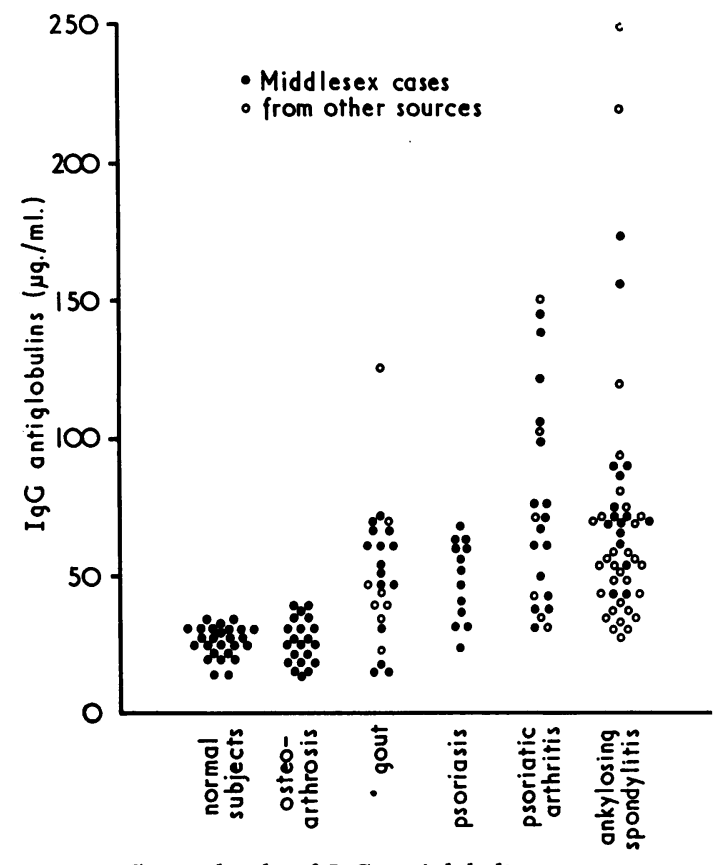

FIGURE Serum levels of IgG antiglobulins

Low concentrations of IgM antiglobulin, between 14 and $25 \mu \mathrm{g} . / \mathrm{ml}$., were detected in six of the cases of ankylosing spondylitis and one gave a value of $65 \mu \mathrm{g}$. $/ \mathrm{ml}$. One patient with gout had $28 \mu \mathrm{g}$. IgM antiglobulin $/ \mathrm{ml}$, and one case of psoriatic arthropathy gave a value of $43 \mu \mathrm{g}$. $/ \mathrm{ml}$.; detectable amounts could not be found in the sera of the other patients.

There was no correlation between IgG antiglobulins and the degree of joint involvement in each group, but there was a relationship with the erythrocyte sedimentation rate in patients with ankylosing spondylitis $(r=0.618 ; \mathrm{P}<0.01)$ but not in those with psoriatic arthropathy $(r=0.387$; n.s. $)$ or uncomplicated psoriasis $(r=0.283$; n.s. $)$, although some correlation held when all three groups were considered together $(r=0.531 ; \mathrm{P}<0.001)$. The extent of skin involvement did not bear any evident relationship to the results in the cases of psoriatic arthropathy or uncomplicated psoriasis, but the serum uric acid levels in the patients with gout did show some correlation with the IgG antiglobulin values $(r=0.545$; $P<0.025)$.

\section{Discussion}

The present results, showing increased IgG antiglobulin levels in patients with psoriatic arthropathy and ankylosing spondylitis, are closely comparable to previous findings in cases of seronegative and seropositive rheumatoid arthritis. This suggests that one final common pathway in the pathogenesis of the inflammatory process may exist in all these conditions. It is currently held that aggregates of IgG provide the stimulus for antiglobulin formation and recent studies have shown the presence of such aggregates in synovial fluids from affected joints. Their uptake by polymorphonuclear cells is accompanied by the release of lysosomal components which can generate a destructive inflammatory lesion. The trigger for IgG aggregation is still to be identified and may be different in each of the disorders mentioned.

The finding of moderately elevated IgG antiglobulin levels in a proportion of patients with gout or psoriasis was unexpected. An immunological reaction involving an infectious agent or an autoantigen could underly the inflammation in psoriasis, but there is as yet no evidence to support this. In the case of gout it is simplest to suppose that the uric acid crystals directly provoke an inflammatory response, but there is some evidence for the activation of immunological processes which accords with our present findings. Thus peripheral blood lymphocytes in 43 per cent. of these patients show increased rosette formation with IgG-coated erythrocytes (Bach, Delrieu, and Delbarre 1970). Furthermore, cell smears from gouty joint effusions contain inclusion bodies staining for immunoglobulins and complement (Barnett, Bienenstock, and Bloch, 1966; Rawson, Abelson, and Hollander, 1965), while elevated immunoconglutinin titres, representing an autoimmune response to bound $C 3$, have been reported in a high percentage of patients with acute primary gout (Bienenstock and Bloch, 1967).

\section{Summary}

Using a technique involving binding to insoluble cross-linked horse IgG, it was shown that patients with psoriatic arthropathy and ankylosing spondylitis have raised levels of IgG antiglobulins, the results being closely comparable to those found in patients with rheumatoid arthritis. It is suggested that the inflammatory process in these conditions may be mediated by a common pathway.

Antiglobulin levels cannot therefore differentiate the arthritis of psoriatic arthorpathy and ankylosing 
spondylitis from that of rheumatoid disease. Moderately raised levels were found in psoriasis and in gout and other evidence for immunological processes in the latter is discussed.

We are grateful to the physicians of The Middlesex
Hospital and Dr. K. N. Lloyd (United Cardiff Hospitals) for allowing us to study their patients. Dr. G. Torrigiani was the holder of a Wates Fellowship. The work was supported by grants from the Medical Research Council and the World Health Organization. We thank Mrs. G. Stead for help in preparation of the manuscript and Miss V. Petts for the illustration.

\section{References}

American Rheumatism Association (1959) Ann. rheum. Dis., 18, 49 (Diagnostic criteria for rheumatoid arthritis)

Bach, J-F., Delrieu, F., and Delbarre, F. (1970) Amer. J. Med., 49, 213 (The rheumatoid rosette. A diagnostic test unifying seropositive and seronegative rheumatoid arthritis)

Barnett, E. V., Bienenstock, J., AND Bloch, K. J. (1966) J. Amer. med. Ass., 198, 143 (Antinuclear factors in synovia. Possible participants in the rheumatoid inclusion body)

BenNetT, P. H., AND BURCh, T. A. (1967) Bull. rheum. Dis., 17, 453 (New York symposium on population studies in the rheumatic diseases: new diagnostic criteria)

BIENENSTOCK, J., AND BLOCH, K. J. (1967) Arthr. and Rheum., 10, 187 (Immunoconglutinin in various rheumatic diseases and certain diseases suspected of an autoimmune pathogenesis)

Rawson, A. J., Abelson, N. M., AND Hollander, J. L. (1965) Ann. intern. Med., 62, 281 (Studies on the pathogenesis of rheumatoid joint inflammation. II. Intracytoplasmic particulate complexes in rheumatoid synovial fluids)

Torrigiani, G., Ansell, B. M., Chown, E. E. A., AND Roitt, I. M. (1969) Ann. rheum. Dis., 28, 424 (Raised IgG antiglobulin factors in Still's disease)

- AND RorT, I. M. (1967) Ibid., 26, 334 (Antiglobulin factors in sera from patients with rheumatoid arthritis and normal subjects)

, - L L Loyd, K. N., AND CorbeTt, M. (1970) Lancet, 1, 14 (Elevated IgG antiglobulins in patients with seronegative rheumatoid arthritis) 